\title{
РЕСУРСОВЕДЕНИЕ
}

DOI: https://doi.org/10.15688/nsr.jvolsu.2021.1.5

UDC 631.4

LBC 40.3

\section{MORPHOLOGICAL FEATURES OF SOILS IN THE YELSHANKA RIVER FLOODPLAIN UNDER CONDITIONS OF URBOTECHNOPEDOGENESIS}

\author{
Oleg A. Gordienko \\ Volgograd State University, Volgograd, Russian Federation \\ Igor V. Manaenkov \\ Volgograd State University, Volgograd, Russian Federation \\ Ilya A. Agapov \\ Volgograd State University, Volgograd, Russian Federation
}

\begin{abstract}
The river system on the territory of Volgograd is represented by eight small rivers. Currently, in the territory of Volgograd there is an active inclusion of valley and floodplain landscapes in the urban area. Under conditions of the anthropogenic impact, the normal regime of valley and floodplain landscapes is disturbed. As a result of changes in the hydrological regime of floodplains and valleys, various morphological transformations of soil cover occur, such as the formation of specific iron and carbonate new formations, etc. As a result of economic activities, modern alluvial soils and sediments are often buried under the thickness of the anthropogenic material. The relevance of the study is due to the high recreational value of valley and floodplain landscapes. The authors analyze 6 soil profiles set up in different parts of the Yelshanka river floodplain. The description of soil sections was $\vec{\delta}$ performed with the use of the Field Qualifier of Soils of Russia. Soil profiles were named in accordance with the Russian Soil Classification and Diagnosis (2004) and the Field Qualifier of Soils of Russia (2008). In Volgograd, as in most cities in Russia and abroad, the study of soils of floodplain landscapes is not systematic, and in some cases is limited to a certain area of research. The purpose of the work was to monitor the morphological state of the floodplain soil cover of the Yelshanka River in order to determine the degree of soils transformation in the area as a result of urbotechnopedogenesis. The studies conducted at the site allow considering that the urban soils of recreational areas are a consequence of the combined effect of zonal natural and climatic and urbanogenic factors of soil formation. Studies of soils of floodplain landscapes in the urban environment make it possible to monitor the state of natural landscapes and their transformation in conditions of urbotechnopedogenesis, as well as the development of the ecological framework of the city.

Key words: Volgograd, alluvial soils, anthropogenic transformation of soils, river valley, classification of soils of Russia.

Citation. Gordienko O.A., Manaenkov I.V., Agapov I.A. Morphological Features of Soils in the Yelshanka River Floodplain Under Conditions of Urbotechnopedogenesis. Prirodnye sistemy i resursy [Natural Systems and Resources], 2021, vol. 11, no. 1, pp. 35-41. DOI: https://doi.org/10.15688/nsr.jvolsu.2021.1.5
\end{abstract}


УДК 631.4

ББК 40.3

\title{
МОРФОЛОГИЧЕСКИЕ ОСОБЕННОСТИ ПОЧВ ПОЙМЫ РЕКИ ЕЛЬШАНКА В УСЛОВИЯХ УРБОТЕХНОПЕДОГЕНЕЗА
}

\author{
Олег Андреевич Гордиенко \\ Волгоградский государственный университет, г. Волгоград, Российская Федерация \\ Игорь Викторович Манаенков \\ Волгоградский государственный университет, г. Волгоград, Российская Федерация

\section{Илья Александрович Агапов} \\ Волгоградский государственный университет, г. Волгоград, Российская Федерация
}

\begin{abstract}
Аннотация. Речная сеть на территории г. Волгограда представлена восьмью малыми реками. На территории г. Волгограда в настоящее время происходит активное включение долинных и пойменных ландшафтов в городскую территорию. В условиях антропогенного воздействия нарушается нормальный режим долинных и пойменных ландшафтов. В результате изменения гидрологического режима территории пойм и долин происходят различные морфологические трансформации почвенного покрова, такие как образование специфических железистых и карбонатных новообразований и др. В результате хозяйственной деятельности современные аллювиальные почвы и отложения часто погребаются под толщей антропогенного материала. Актуальность исследования обусловлена высокой рекреационной значимостью долинных и пойменных ландшафтов. В работе были изучены 6 почвенных профилей, заложенных в различных участках поймы р. Ельшанка. Описание почвенных разрезов выполнялось с использованием полевого определителя почв России. Названия почв даны в соответствии с Классификацией и диагностикой почв России 2004 г. и полевого определителя почв России 2008 г. В Волгограде, как и в большинстве городов России и зарубежья, изучение почв пойменных ландшафтов носит несистемный характер, и в ряде случаев ограничивается определенной областью исследования. Целью работы являлся мониторинг морфологического состояния почвенного покрова поймы р. Ельшанка с целью установления степени трансформации почв территории в следствии урботехнопедогенеза. Исследования, проведенные на объекте, позволяют считать, что городские почвы рекреационных территорий являются следствием одновременного влияния зональных природно-климатических и урбаногенных факторов почвообразования. Исследования почв пойменных ландшафтов в городской среде дает возможность производить мониторинг за состоянием природных ландшафтов и их трансформацию в условиях урботехнопедогенеза, а также разработки системы экологического каркаса города.
\end{abstract}

Ключевые слова: Волгоград, аллювиальные почвы, антропогенная трансформация почв, речная долина, классификация почв России.

Цитирование. Гордиенко О. А., Манаенков И. В., Агапов И. А. Морфологические особенности почв поймы реки Ельшанка в условиях урботехнопедогенеза // Природные системы и ресурсы. -2021 . - Т. 11, № 1. - C. 35-41. -DOI: https://doi.org/10.15688/nsr.jvolsu.2021.1.5

\section{Введение}

Речная сеть на территории г. Волгограда представлена восьмью малыми реками. Активное включение в городскую территорию долинных, в частности, пойменных ландшафтов обусловлено рядом социально-экономических причин. Вследствие чего нарушается естественное функционирование долинных массивов, а аллювиальные почвы и отложения, как правило, трансформируются или, погребают- ся антропогенной толщей. Трансформация естественного рельефа связано также с вертикальной планировкой территории, засыпкой оврагов, устьев рек [3].

Ельшанка - малая река в Волгограде правый приток Волги. Река является границей между Ворошиловским и Советским районами города. На всем протяжении река течет параллельно железной дороге. Русло большей частью замыто и засыпано. Нижняя часть русла целиком скрыта в ливневых 
коллекторах. Целью работы является мониторинг морфологического состояния почвенного покрова поймы р. Ельшанка с целью установления степени трансформации почв территории в следствии урботехнопедогенеза.

Объектом исследования являлись почвы поймы р. Ельшанка. Предметом - трансформация почвенного покрова при разном уровне антропогенной нагрузки на территории поймы.

\section{Материал и методы}

В работе были изучены 6 почвенных профилей, заложенных в различных участках поймы р. Ельшанка (рис. 1). Описание почвенных разрезов выполнялось с использованием полевого определителя почв России. Названия почв даны в соответствии с Классификацией и диагностикой почв России 2004 г. (КиДПР) и полевого определителя почв России 2008 г. [5].

\section{Результаты и обсуждение}

В Волгограде, как и в большинстве городов России и зарубежья, изучение почв пойменных ландшафтов носит несистемный характер, и в ряде случаев ограничивается определенной областью исследования $[1 ; 8]$. Комплексное исследование, которое бы включало в себя картографирование, физические, химические, санитарно-гигиенические, биологические исследования свойств почв и определение их

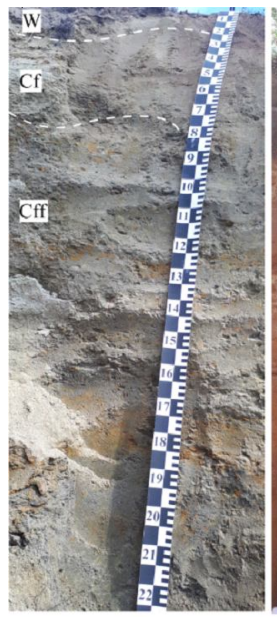

E1

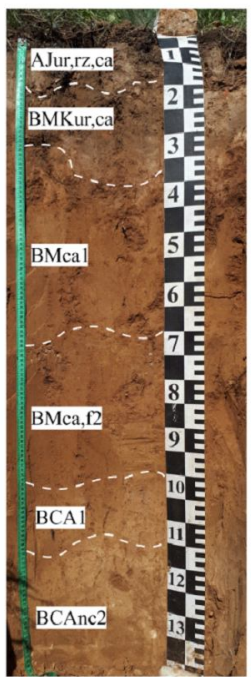

E4

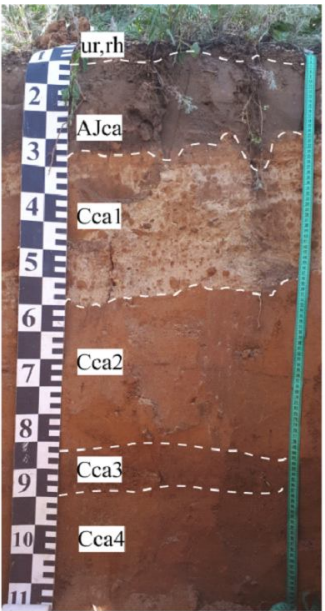

E2

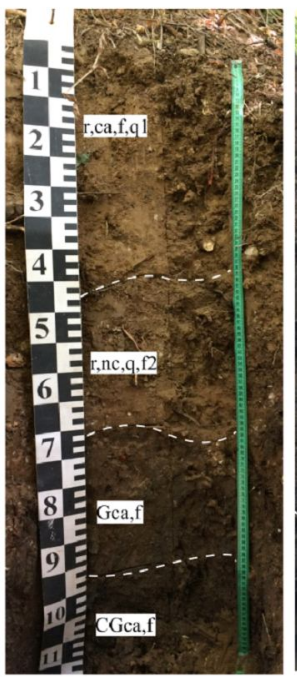

E5

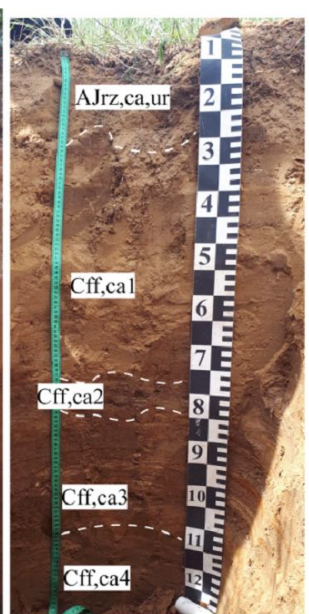

E3

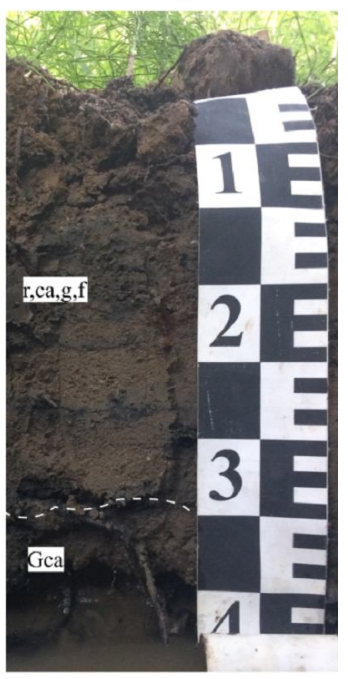

E6

Рис. 1. Почвенные разрезы поймы р. Ельшанка 


\section{РЕСУ РСОВЕДЕНИЕ}

классификационного положения в различных почвенных систематиках проводилось в Москве и Санкт-Петербурге [2; 4; 6; 7].

В работе были изучены 6 почвенных профилей, заложенных в различных участках поймы р. Ельшанка. Разрез Е1 представлен насыпью и расположен в 5 м от ж/д путей. Почвообразующие породы представлены песчаными отложениями. Верхние 10 см профиля представлены маломощным горизонтом начальных стадий аккумуляции гумуса. Нижняя часть профиля слагается из транспортиртированных песчаных слоев. Присутствие в них железистых новообразований обусловлено наличием в толще линии водоснабжения. Данная почва имеет антропогенный генезис поскольку образована путем целенаправленной транспортировки рыхлых геологических отложений для строительства ж/д путей и прокладки линии водоснабжения. Наличие на дневной поверхности горизонта начальных стадий аккумуляции гумуса и нижерыхлой породы песчаного гранулометрического состава позволяет отнести данную почву к отделу слаборазвитых почв к типу псаммоземов гумусовых к псевдофибровому подтипу.

Разрез Е2 заложен в 10 м от железнодорожной насыпи на склоне. Почвообразующие породы представлены аллювиальными карбонатными отложениями. В целом несмотря на наличие рядом крупного антропогенного объекта (ж/д пути) почва исследуемого разреза естественная. Верхняя часть разреза представлена маломощным (4 см) слоем антропогенных включений и дернины. Вскипание от $\mathrm{HCl}$ отмечается с поверхности. Антропогенные включения представлены преимущественно бытовым и строи- тельным мусором. Ниже располагается супесчаный светлогумусовый горизонт АЈса. Под ним залегают слои аллювиальных отложений, содержащих карбонатную пропитку. Начиная с 76 до 93 см фиксируется погребенный горизонт AJca2 более темной окраски чем выше и нижележащие слои. Сочетание гумусового горизонта и ниже слоистых аллювиальных отложений позволяет отнести данную почву к стволу синлитогенного почвообразования к отделу аллювиальных почв к аллювиальному светлогумусовому типу к урбостратифицированному подтипу. В актуальной версии КиДПР, а также Полевого определителя почв нет аллювиальных почв со светлогумусовым горизонтом, однако по цветовому и морфологическому описанию верхний гумусо-аккумулятивный горизонт разреза Е2 идентифицирован нами как светлогумусовый (АЈ).

Разрез Е3 заложен в 50 м от разреза E2. Почвообразующие породы представлены аллювиальными ожелезнененными карбонатными отложениями. Разрез на типовом уровне идентичен разрезу E2, однако на подтиповом уровне заметно отличается, поскольку процессы, протекающие в нем, существенно изменили морфологические характеристика почвенных горизонтов. На дневной поверхности расположен светлогумусовый горизонт, полностью пронизанный корнями травянистых растений, а также содержащий с поверхности антропогенные включения в виде строительного и бытового мусора. Расположенные ниже слои аллювиальных отложений отличаются от слоев в разрезе Е2 более высокой степенью увлажнения, а также наличием железистых новообразований в видепсевдофибр диаметром 0,1-0,2 см (рис. 2). На глубине 75-82 см фик-

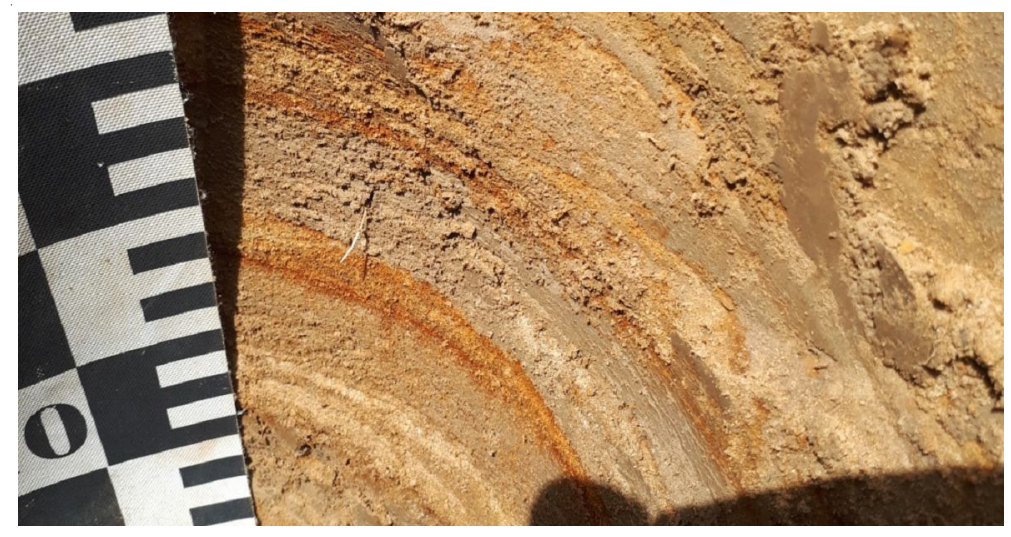

Рис. 2. Железистые новообразования в виде псевдофибр в разрезе Е3 
сируется погребенный горизонт AJff,ca2. Данный разрез идентифицирован нами как аллювиальная светлогумусовая псевдофибровая урбостратифицированная почва.

Разрез Е4. Почвообразующие породы представлены карбонатными лессовидными суглинками. Поскольку разрез находится на более высоком участке поверхности чем остальные пойменный процесс не участвовал в формировании данной почвы. Сверху располагается светлогумусовый горизонт светлосерого цвета с признаками урботехнопедогенеза в виде включений строительного и бытового мусора. Ниже него - ксерометаморфический горизонт BMKur, также содержащий антропогенные включения. Горизонт мелкокомковатой структуры, легкосуглинистого гранулометрического состава, вскипание сплошное, что свидетельствует о наличии карбонатной пропитки. С глубины 34 см нами выделен структурно-метаморфический горизонт ВМ. Горизонт разделен нами на два поскольку, начиная с 64 см в горизонте фиксируются железистые новообразования, а также включения в виде ракушек. Вскипание в горизонте сплошное, структура преимущественно глыбистая. Ниже располагаются два аккумулятивно-карбонатных горизонта ВСА, однако во втором (BCAnc2) начиная с глубины $110 \mathrm{~cm}$ морфологически выделены сегрегационные формы карбонатных новообразований различного диаметра, тогда как в вышележащем (BCA1) они преимущественно в форме карбонатной пропитки. Сочетания ксерометаморфического и аккумулятивно-карбонатного горизонтов позволяет отнести данную почву к отделу светлогумусовых аккумулятивно-карбонатных почв к каштановому типу к урбостратифицированному подтипу.

Разрез Е5 заложен на склоне вниз к днищу балки. Почвообразующие породы представлены делювиальными карбонатными отложениями. Начиная с поверхности и до 36 см нами выделен малый стратифицирующий признак rl темных тонов, комковатой структуры, тяжелого гранулометрического состава, бурно вскипающий от $\mathrm{HCl}$ и содержащий оливковые пятна оглеения. Под ним расположен второй стратифицирующий признак (r2) отличающийся от первого выделением в почвенной массе карбонатных новообразований сегрегационной формы. Оба признака характеризуются наличием железистых новообразований. Под ними залегает плотный глинистый глеевый горизонт темно-серой окраски. В почвенной массе горизонта фиксируется обилие неразложившихся органических остатков, а также мучнистые формы карбонатных новообразований. С 88 см выделен переходный к почвообразующей породе горизонт CGf,ca. Новообразования по большей части идентичны вышележащему, однако выше насыщенность влагой и отсутствуют вторичные карбонатные новообразования. Наличие на дневной поверхности стратифицирующего материала позволяет отнести данный почвенный профиль к отделу стратоземов к типу стратоземов светлогумусовых и глееватому подтипу.

Разрез Е6 заложен в днище поймы. Почвообразующие породы представлены карбонатными аллювиальными отложениями. Верхняя часть профиля представлена слоистым бесструктурным материалом, содержащим ржавые и черные пятна, а также большое количество слаборазложившихся органических остатков. Начиная с $31 \mathrm{~cm}$ и до 40 см выделен глеевый горизонт сырой, супесчаный с черными мажущими пятнами от неразложившихся органических остатков. Поскольку разрез заложен в днище поймы грунтовые воды в нем начинаются с 40 см. Данный почвенный разрез классифицирован нами как стратозем светлогумусовый глееватый.

\section{Заключение}

Таким образом, проанализировав морфологические особенности почвенных разрезов территории поймы р. Ельшанка можно сделать следующие выводы:

1. Почвенный покров территории несет на себе отпечаток структуры и характера землепользования и представляет собой многообразие почвенных комбинаций как природного, так и антропогенного происхождения.

2. При проведении исследований на территории исследования было установлено, что во всех почвенных разрезах обнаружен ряд признаков антропогенной трансформации почв. Однако для каждого из разрезов степень трансформации была разной. 


\section{РЕСУ РСОВЕДЕНИЕ}

3. Для всех исследуемых почвенных разрезов характерно наличие в верхней части профиля маломощного (до 5 см) антропогенного слоя, образованного естественной аккумуляцией пылеватых частиц и твердого бытового мусора.

Исследования почв пойменных ландшафтов в городской среде дает возможность производить мониторинг состояния природных ландшафтов и их трансформации в условиях урботехнопедогенеза, что служит основой для разработки системы экологического каркаса города.

\section{СПИСОК ЛИТЕРАТУРЫ}

1. Герасимова, М. И. Признаки природной и антропогенной эволюции в микростроении почв Быковского расширения Москворецкой поймы / М. И. Герасимова, Н. В. Савицкая // Почвоведение. - 2020. - № 7. - С. 860-870. - DOI: http:// dx.doi.org/ 10.31857/S0032180X20070035.

2. Иванников, Ф. А. Техногенные почвоподобные тела речной долины и их трансформация в условиях города (на примере долины р. Москвы) / Ф. А. Иванников, Т. В. Прокофьева // Вестник Московского университета. Серия 17, Почвоведение. 2010. - № 4. - C. 10-15.

3. Коростелева, Н. В. Градостроительный потенциал пойменных территорий малых рек на примере города Волгограда / Н. В. Коростелева, Р. Р. Бикмухамедова // Вестник Волгоградского государственного архитектурно-строительного университета. Серия: Строительство и архитектура. - 2017. T. 47, № 66. - C. 495-504.

4. Морфологическая диагностика почвообразования в поймах рек на территории г. Москвы / Т. В. Прокофьева [и др.] // Почвоведение. -2010.№ 4. - C. 399-411. - DOI: http://dx.doi.org/10.1134/ S1064229310040022.

5. Полевой определитель почв России. - М. : Почв. ин-т им. В.В. Докучаева, 2008. -182 с.

6. Прокофьева, Т. В. Долина Москвы-реки и почвы столицы / Т. В. Прокофьева, О. А. Варава // Природа. - 2013. - Т. 6, № 1174. - С. 33-43.

7. Ecotoxicological state and pollution status of alluvial soils of St. Petersburg, Russian Federation / V. Polyakov [et al.] // Soil Science Annual. - 2020. Vol. 71, № 3. - P. 221-235. - DOI: https://doi.org/ $10.37501 /$ soilsa/127089.

8. Mapping and assessment of sealing rate of soils in the city of Volgograd / O. A. Gordienko [et al.] // Eurasian Soil Sci. - 2019. - № 11. - C. 1439-1446. DOI: https://doi.org/10.1134/S106422931911005X.

\section{REFERENCES}

1. Gerasimova M.I., Savitskaya N.V. Priznaki prirodnoj i antropogennoj evolyucii v mikrostroenii pochv Bykovskogo rasshireniya Moskvoreckoj pojmy [Micromorphological interpretation of natural and anthropogenic evolution of soils in Bykovo lacustrine-alluvial section of the Moscow river floodplain]. Pochvovedenie [Eurasian Soil Sci], 2020, no. 7, pp. 860-870. DOI: http://dx.doi.org/10.31857/ S0032180X20070035.

2. Ivannikov F.A., Prokofieva T.V. Tekhnogennye pochvopodobnye tela rechnoj doliny $\mathrm{i}$ ih transformaciya $\mathrm{v}$ usloviyah goroda (na primere doliny r. Moskvy) [Properties and evolution of artificial soil-like bodies of Moscowriver valley in the urban environment]. Vestnik Moskovskogo universiteta. Seriya 17, Pochvovedenie [Moscow University Soil Science Bulletin], 2010, no. 4, pp. 10-15.

3. Korosteleva N.V., Bikmuhamedova R.R. Gradostroitel'nyj potencial pojmennyh territorij malyh rek na primere goroda Volgograda [Urban development potential of floodplain territories of small rivers by the example of the city of Volgograd]. Vestnik Volgogradskogo gosudarstvennogo arhitekturnostroitel'nogo universiteta. Seriya: Stroitel'stvo $i$ arhitektura [Bulletin of Volgograd state university of architecture and civil engineering], 2017, no. 47 (66), pp. 495-504.

4. Prokof'eva T.V., Varava O.A., Sedov S.N., Kuznecova A.M. Morfologicheskaya diagnostika pochvoobrazovaniya $\mathrm{v}$ pojmah rek na territorii $\mathrm{g}$. Moskvy [Morphological diagnostics of pedogenesis on the anthropogenically transformed floodplains in Moscow]. Pochvovedenie [Eurasian Soil Sci], 2010, no. 4, pp. 399-411. DOI: http://dx.doi.org/10.1134/ S1064229310040022.

5. Polevoy opredelitel pochv Rossii [Field determinant of soils of Russia]. Moscow, V.V. Dokuchaev Soil Science Institute, 2008. 182 p.

6. Prokofieva T.V., Varava O.A. Dolina Moskvyreki i pochvy stolicy [Valley of the Moscow river and soils of the capital]. Priroda, 2013, no. 6(1174), pp. 33-43.

7. Polyakov V., Reznichenko O., Kostecki J., Abakumov E. Ecotoxicological state and pollution status of alluvial soils of St. Petersburg, Russian Federation. Soil Science Annual, 2020, no. 71 (3), pp. 221-235. DOI: https://doi.org/10.37501/soilsa/ 127089.

8. Gordienko O.A., Manaenkov I.V., Kholodenko A.V., Ivantsova E.A.Mapping and Assessment of Sealing Rate of Soils in the City of Volgograd. Eurasian Soil Sci, 2019, no. 11, pp. 14391446. DOI: http://dx.doi.org/10.1134/ S106422931911005X. 


\section{Information About the Authors}

Oleg A. Gordienko, Assistant Lecturer, Department of Ecology and Nature Management, Volgograd State University, Prosp. Universitetsky, 100, 400062 Volgograd, Russian Federation, oleg.gordienko.95@bk.ru

Igor V. Manaenkov, Candidate of Sciences (Biology), Associate Professor, Department of Ecology and Nature Management, Volgograd State University, Prosp. Universitetsky, 100, 400062 Volgograd, Russian Federation, manaenkov@volsu.ru

Ilya A. Agapov, Master Student, Department of Ecology and Nature Management, Volgograd State University, Prosp. Universitetsky, 100, 400062 Volgograd, Russian Federation, weathermaker@yandex.ru

\section{Информация об авторах}

Олег Андреевич Гордиенко, ассистент кафедры экологии и природопользования, Волгоградский государственный университет, просп. Университетский, 100, 400062 г. Волгоград, Российская Федерация, oleg.gordienko.95@bk.ru

Игорь Викторович Манаенков, кандидат биологических наук, доцент кафедры экологии и природопользования, Волгоградский государственный университет, просп. Университетский, 100, 400062 г. Волгоград, Российская Федерация, manaenkov@volsu.ru

Илья Александрович Агапов, магистрант кафедры экологии и природопользования, Волгоградский государственный университет, просп. Университетский, 100, 400062 г. Волгоград, Российская Федерация, weathermaker@yandex.ru 